最大自転車駆動と走運動にみられる呼吸

・循環機能の反応の違いに関する研究

\author{
山地 啓 司* 宮下 充 正**
}

（昭和50年10月9 日 受付）

\title{
A Study on the Difference in Cardio-Respiratory Responses to the Maximum Work between Cycling and Running
}

\author{
Keiji Yamaji (Faculty of Education, Toyama University) \\ Mitsumasa Miyashita (Faculty of Education, University of Tokyo)
}

\begin{abstract}
The present study was intended to compare cardio-respiratory responses to the maximal exercise on bicycle with those on treadmill. The progressive loading method was adopted for both bicycle exercise and treadmill running (resistance for bicycle and speed for treadmill). The subjecte were 28 well-trained middle and long distance male runners, aged 18 to 25 years. Douglas bags and Scholander's apparatus were used to determine the maximal oxygen uptake. The modified Filley's steady state method was adopted for the determination of pulmonary diffusing capacity, and $\mathrm{CO}_{2}$ rebreathing method was for the determination of cardiac output. The results obtained in this study were summarized as follows;

1) The maximal oxygen uptake $(3.93 \pm 0.471 / \mathrm{min})$ obtained by treadmill running was significantly greater than that $(3.36 \pm 0.501 / \mathrm{min})$ by bicycle exercise.

2) The larger maximal oxygen uptake by treadmill running was due to the higher pulmonary diffusing capacity, ventilation, heart rate and/or arterial-venous oxygen difference than those by bicycle exercise.

(Keiji Yamaji and Mitsumasa Miyashita: A Study on the Difference in Cardio-Respiratory Responses to the Maximum Work between Cycling and Running. Jap. J. Phys. Educ., Vol. 22, No. 4, Nov., 1977, pp. 179 187)
\end{abstract}

\section{I}

全身持久生の作業能力の最良の指根の一つとし てみられている取大醅来摄取量は，娜定を行な5

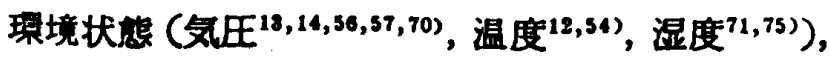
作業模式 (トレッドミル走18,42,50)，自枟車駆動9,

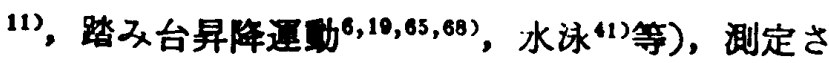

れる被検者の 身体的・精神的状热 $1,40,40,01,02,63)$ 等 Кよって翼なってくろ.これまでこれらの樶大 酸菜措取量を增娍させる機序を究明する試及がな されてきたがかならずしる一政した見解が得ら れていない. 3, 10, 16, 17, 24, 26, 38, (33,47,64)

本研究は中・長距鹤摆手を対象として，自枟車 㪙動とトレッドミル走とにみられる呼吸・循璣

\footnotetext{
*富山大学教育学部 **東宗大学数育学部
} 
地の反応の相进を粉合的に梌討することによっ て，酸来振取旦の生理的碳序を明らかにしようと するものである。

\section{开宽方法}

\section{（1）被湌者}

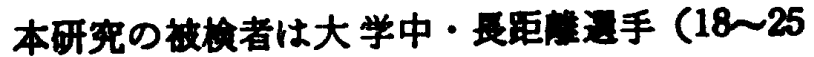
塂）の男子28名である. その身体的特性は Table

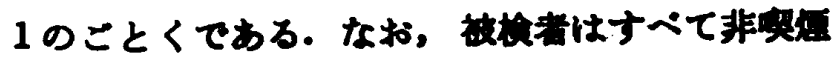
者である.

Table 1. Physical characteristics of the subjects.

\begin{tabular}{l|r|rrrr}
\hline & & $\begin{array}{c}\text { Height } \\
(\mathrm{cm})\end{array}$ & $\begin{array}{c}\text { Weight } \\
(\mathrm{kg})\end{array}$ & $\begin{array}{c}\text { B.S.A. } \\
(\mathrm{m})\end{array}$ & $\begin{array}{c}\text { VC } \\
\text { (1) }\end{array}$ \\
\hline Athletes & mean & 168.5 & 58.3 & 1.67 & 4.48 \\
(28 male) & S.D. & 4.4 & 4.5 & 0.09 & 0.60 \\
\hline
\end{tabular}

（2）润定方法

(a) 作菜方法

トレッドミル走は，ます樶初の具何 (180〜210

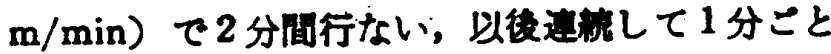

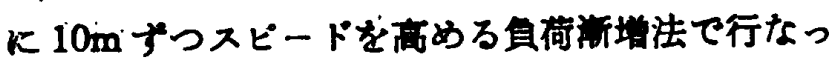
た.なお、トレッドミルの傾鲜は 5 度 $(8.6 \%)$ と した.

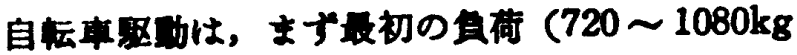

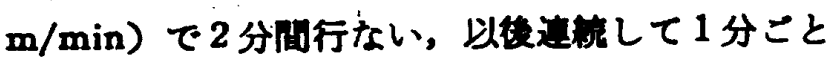

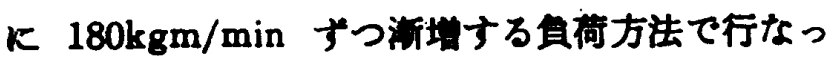
た。なお，敒用した自枟車はモナーク社整で，へ タルの回枟数は $60 \mathrm{rpm}$ とした。两作莱における exhaustionはす心ての被湌者において速期開始後 5 分から 8 分以内に思められた。

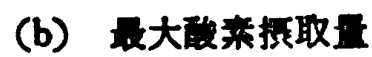

exhaustion $2 \sim 3$ 分前から exhaustion に逢す ろまで，1分こととに呼気ガスをダグラスパッグに 探集した。探した呼気ガスを乾式ガスハーター て， $\mathrm{O}_{2}$ および $\mathrm{CO}_{2}$ 潍度を Scholander 微量ガ ス分析器で分析ナることによって最大酸来振取昷 を算出した。

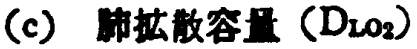

酸来颃取昷の則定と同期して行なった，exhaustion $1 \sim 2$ 分前からCO 混合ガス（空気ガス十 0.05\%の一䂾化庆菜) 孝吸わせた。吸気および呼 気ガス CO 溜度は Beckman CO Analyzerで分析

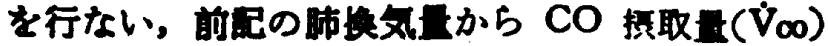
を算出した。 exhaustion 㿭ただちに, LB-1 CO2 Analyzer を用い，Haldane-Priestly 法に上って

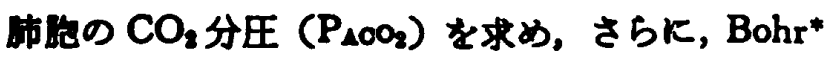

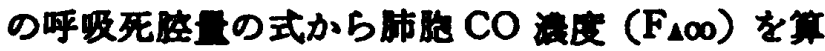

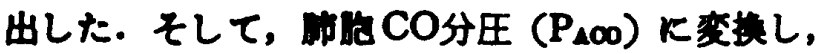

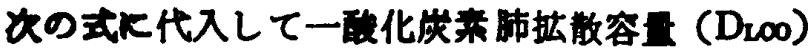
を算出した ${ }^{200}$.

$$
\left.D_{100}=\nabla_{00} / P_{\Delta 00}-P_{0 \infty}^{-}\right)
$$

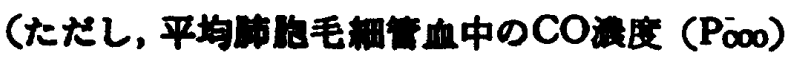
は平とみなしだ").)さらに，次の式に代入して酸

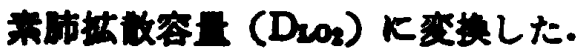

$$
D_{102}=D_{100} \times 1.23
$$

(d) 心拍出兵 (Q)

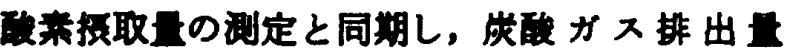

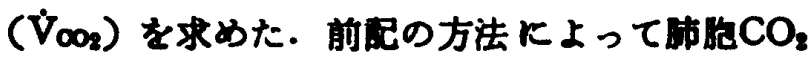

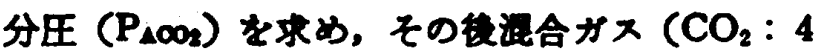
〜 5\%， $\mathrm{O}_{2}:$ :96〜95\%) の再呼吸を行なわせ，涅

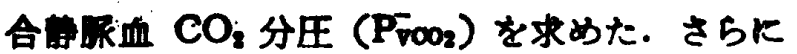

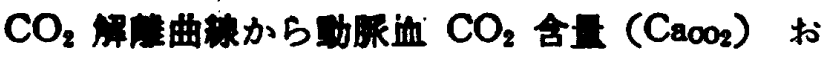

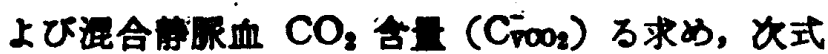
に代入して毎分心拍出年を求めた”．

$$
\dot{Q}=\dot{V}_{\mathrm{OO}_{2} /}\left(\mathrm{C}_{\mathrm{NOO}_{2}}^{-}-\mathrm{C}_{20 \mathrm{OO}_{2}}\right)
$$

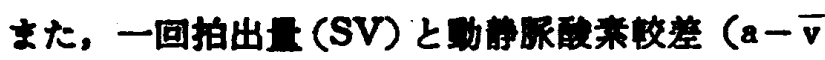
$\mathrm{O}_{2}$ diff.) 施の式に上って罱出した。

$$
\begin{aligned}
& S V=Q / H R \ldots \ldots \ldots \ldots \\
& 2-\bar{\nabla}_{2} \text { diff. }=\dot{V}_{O_{2}} / Q
\end{aligned}
$$

(e) 心拍数 (HR)

心拍数は exhaustion 前 15秒间胸部敌基から心

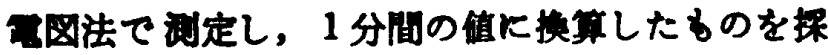
用した。

$$
\text { 结来 }
$$

トレッドミル走および自忶車堪動での最大作澲

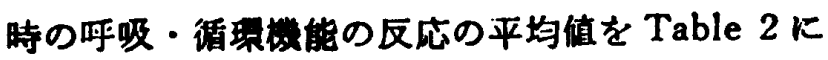
示した。

(1) 最大酸来提取量

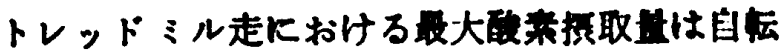

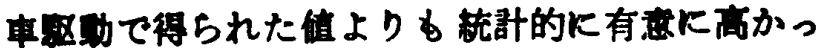
た.トレッドミル走での取大酸来提取量に対する

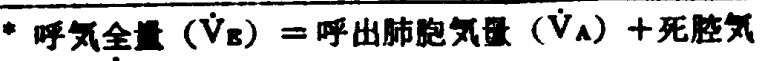
$\left(\dot{V}_{D}\right)$ 


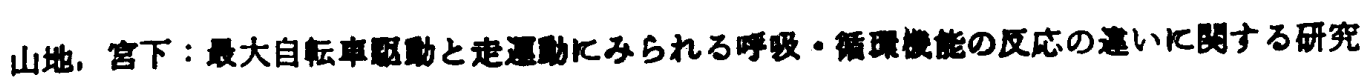

Table 2. Mean values for cardio-respiratory responses to the maximal exercises on both bicycle and treadmill.

\begin{tabular}{|c|c|c|c|c|c|c|c|c|c|c|}
\hline & & $\underset{(1 / \min )}{\max }$ & 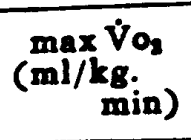 & $\underset{(1 / \min )}{\dot{\mathbf{V}}_{\mathbf{E}}}$ & $\begin{array}{c}\mathrm{O}_{2} R \\
(\mathrm{ml} / \mathrm{l})\end{array}$ & $\begin{array}{c}\mathrm{D}_{\mathrm{LO}_{2}} \\
(\mathrm{ml} / \mathrm{min} \\
\left./ \mathrm{mm} \mathrm{H}_{\mathrm{g}}\right)\end{array}$ & $(1 / \min )$ & $\begin{array}{c}\text { SV } \\
\text { (ml) }\end{array}$ & $\begin{array}{c}\text { HR } \\
\text { (beats/ } \\
\text { min) }\end{array}$ & 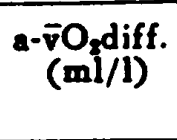 \\
\hline \multirow{2}{*}{ Treadmill } & mean & 3.93 & 67.1 & 144.3 & 32.7 & 63.6 & 27.4 & 143.2 & 191.5 & 142.1 \\
\hline & S.D. & 0.47 & 5.8 & 21.4 & 3.4 & 11.2 & 2.8 & 13.0 & 5.9 & 7.9 \\
\hline \multirow{3}{*}{ Bicycle } & mean & 3.36 & 57.7 & 109.1 & 37.6 & 52.6 & 26.0 & 140.8 & 183.3 & 129.2 \\
\hline & S.D. & 0.50 & 7.0 & 21.8 & 5.0 & 10.3 & 2.6 & 12.4 & 7.7 & 9.7 \\
\hline & & +4 & $* * *$ & $* * *$ & $* *$ & $* * *$ & NS & NS & $* * *$ & $* * *$ \\
\hline
\end{tabular}

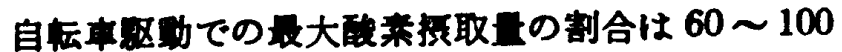
\%に分布し，平均83.0\%であった(Fig. 1 ).

(2) 呼吸栋能

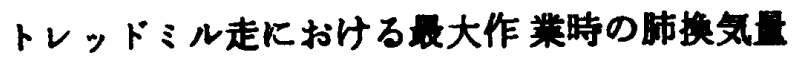
は自枟事取㽖における值よりる梳計的に有意に高 かった。しかし，酸来摄取慗においては自枟車眼 助の方がトレッドミル走に比べ統計的に有意に高 い值を示した。さらに、トレッドミル走における

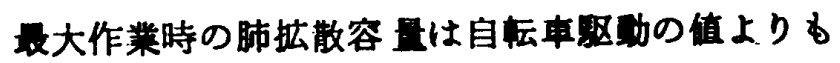
有意に高かった。しかし.肺肥の $\mathrm{O}_{2}$ 分王と肺毛

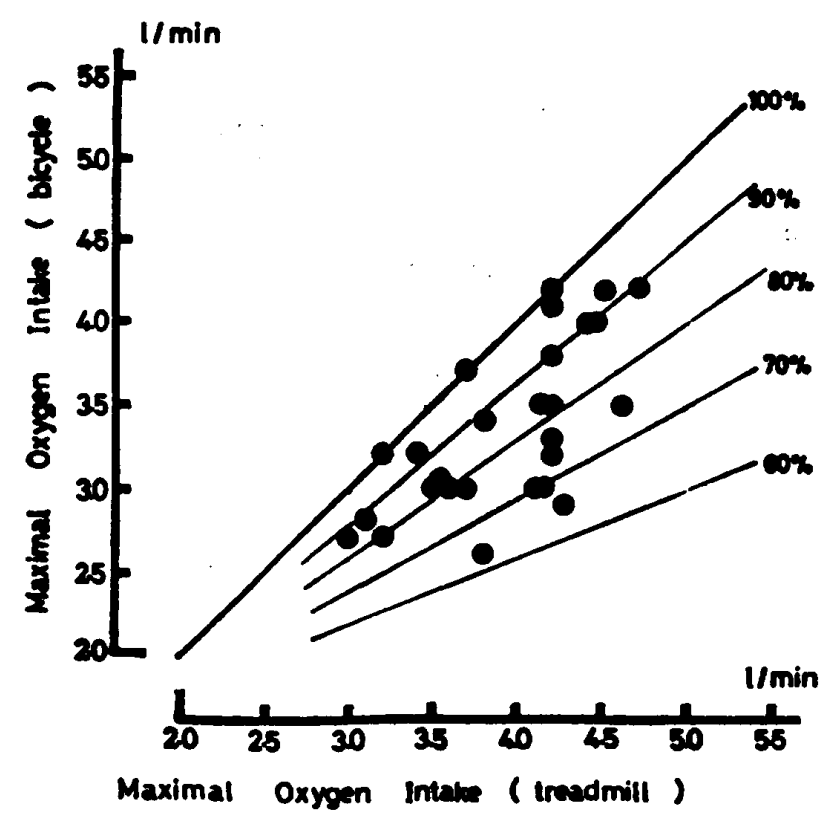

Figure 1. Individual values for maximal oxygen uptake during maximal bicycle exercise compared with the corresponding values during maximal treadmill running.
細管血 $\mathrm{O}_{2}$ 分圧との较差 $\left(\mathrm{P}_{\mathrm{AO}_{2}}-\mathrm{P}_{\mathrm{OO}_{2}}^{-}\right)$て情再作 萧の間に有意な差が照められなかった。

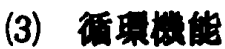

トレッドミル走の最大作業における心拍出每お よび一回拍出年はそれそれ自枟車証功の倠との间 に柾計的に有意な差が琩められなかった。しか し，トレッドミル走における即大作唪時の心拍数

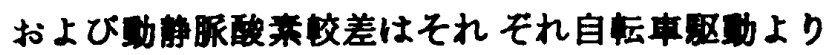
す䒧計的に有意に高い值を示した。

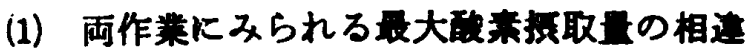

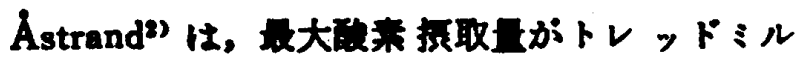

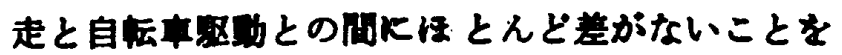

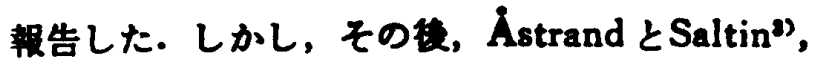

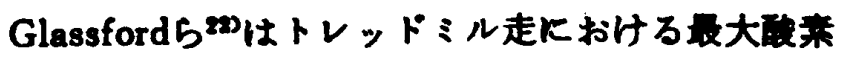

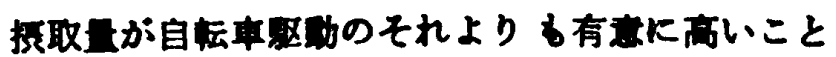

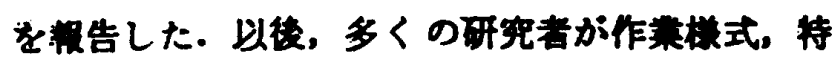

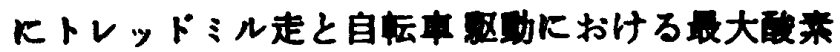
掭取量の差異について検封し，トレッドミル走の

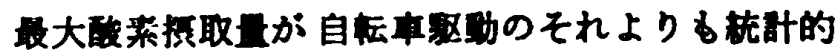
に高いことを啹している(Table 3). Table 3 に゙

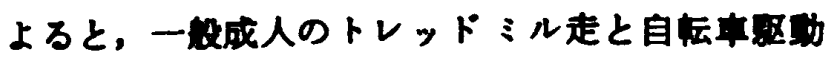

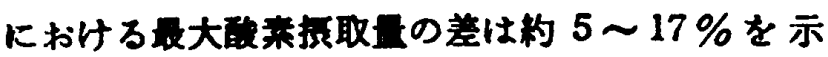
し、五娌䞮手ではボート这手の - $0.4 \%$ から本研

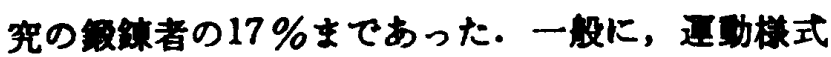

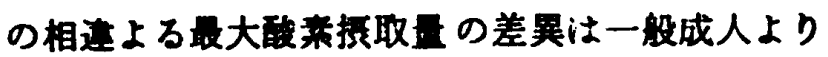

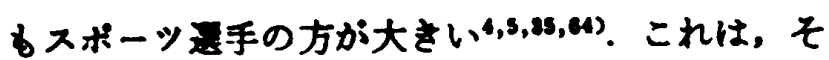
れモれのスポーツ租目别トレーニングよって政 
Table 3. Mean values for maximal oxygen uptake during maximal bicycle exercise compared with the corresponding values during maximal treadmill running.

\begin{tabular}{|c|c|c|c|c|c|c|c|}
\hline \multirow[t]{2}{*}{ Authors } & & \multirow[t]{2}{*}{ Subjects } & \multirow[t]{2}{*}{ No } & \multirow{2}{*}{$\begin{array}{l}\text { Age } \\
\text { years }\end{array}$} & $\begin{array}{c}\text { Treadmill } \\
\text { (A) }\end{array}$ & $\begin{array}{c}\text { Bicycle } \\
\text { (B) }\end{array}$ & $\frac{(\mathrm{A})-(\mathrm{B})}{(\mathrm{B})} \times 100$ \\
\hline & & & & & $1 / \mathrm{min}$ or & $\mathrm{ml} / \mathrm{kg} \cdot \mathrm{min}$ & $\%$ \\
\hline Àstrand 23 & 1961 & normal male & 5 & $22-37$ & 4.69 & 4.47 & 4.9 \\
\hline Newton ${ }^{51)}$ & 1963 & normal male & 7 & $19-70$ & 46.1 & 43.7 & 5.5 \\
\hline Wyndham"4) & 1966 & normal male & 40 & & 3.08 & 2.84 & 8.5 \\
\hline Magel(4) & 1967 & trained swimmers & 26 & $19.8 \pm 1.0$ & 55.5 & 55.0 & 0 \\
\hline Shephard ${ }^{(6)}$ & 1968 & normal male & 24 & $20-40$ & 3.81 & 3.56 & 7.0 \\
\hline Hermansen ${ }^{253}$ & 1969 & endurance athletes & 8 & 21.27 & 5.04 & 4.63 & 8.9 \\
\hline & & trained students & & & 3.54 & 3.17 & 11.7 \\
\hline & & labolatory staff & & $22-40$ & 4.65 & 4.34 & 7.1 \\
\hline & & orienteering & 10 & young & 4.75 & 4.55 & 4.4 \\
\hline & & orienteering & 14 & $45-68$ & 3.68 & 3.44 & 7.0 \\
\hline Hermansen ${ }^{263}$ & 1970 & athletes & 13 & $19-34$ & 4.57 & 4.31 & 6.0 \\
\hline McArdle $(\theta)$ & 1970 & athletes & 23 & 20.41 .8 & 3.27 & 2.95 & 10.8 \\
\hline Pugh"os & 1972 & mountaineers & 5 & $30-39$ & 3.28 & 3.24 & 1.2 \\
\hline Holmer ${ }^{27}$ & 1972 & swim trained & 13 & $16-21$ & 4.48 & 4.18 & 7.2 \\
\hline Miyamurat7 & 1972 & students & 17 & $18-23$ & 3.95 & 3.37 & 17.2 \\
\hline MeAdle ${ }^{(s)}$ & 1973 & students & 15 & 21.94 .0 & 4.11 & 3.68 & 11.7 \\
\hline Katch $^{203}$ & 1974 & college men & 50 & 21.21 .6 & 3.95 & 3.44 & 14.8 \\
\hline Carey") & 1974 & Harvard crew & 5 & 20.81 .9 & 5.34 & 5.32 & -0.4 \\
\hline Present study & 1975 & distant sunners & 28 & $18-25$ & 3.93 & 3.36 & 17.0 \\
\hline
\end{tabular}

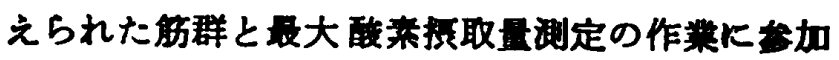
ナる群群とが.かならずしす一致しないことによ ろものと考えられる。

本研究のトレンドミル起と自枟車为为の大酸 来颃取吾の差具が17\%と大きいことは，対象者の

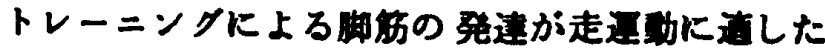
あのであるに対して，自枟車取功の最大作筆では

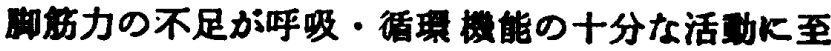

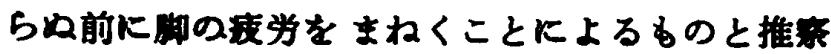
される.しかしこの点についてはさらに検郡が 必票であろ5。

（2）呼吸・循環反応からみたその要因

トレッドミル走と自枟車取娌にみられる最大酸 来掫取年の相䢖の原因に間するこれまでの啹告を 呼吸系から分類してみると，(1)主に酸来掫取事の

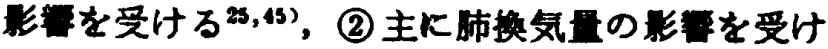
る20)，とい52つの見解に区分される。本研究結 果ではトレッドミル走における最大作業時の肺 换気量は白枟車駆動よりる多いが，酸美摄取率は 自枟車婜動のそ机よりる低い。このことは速動様

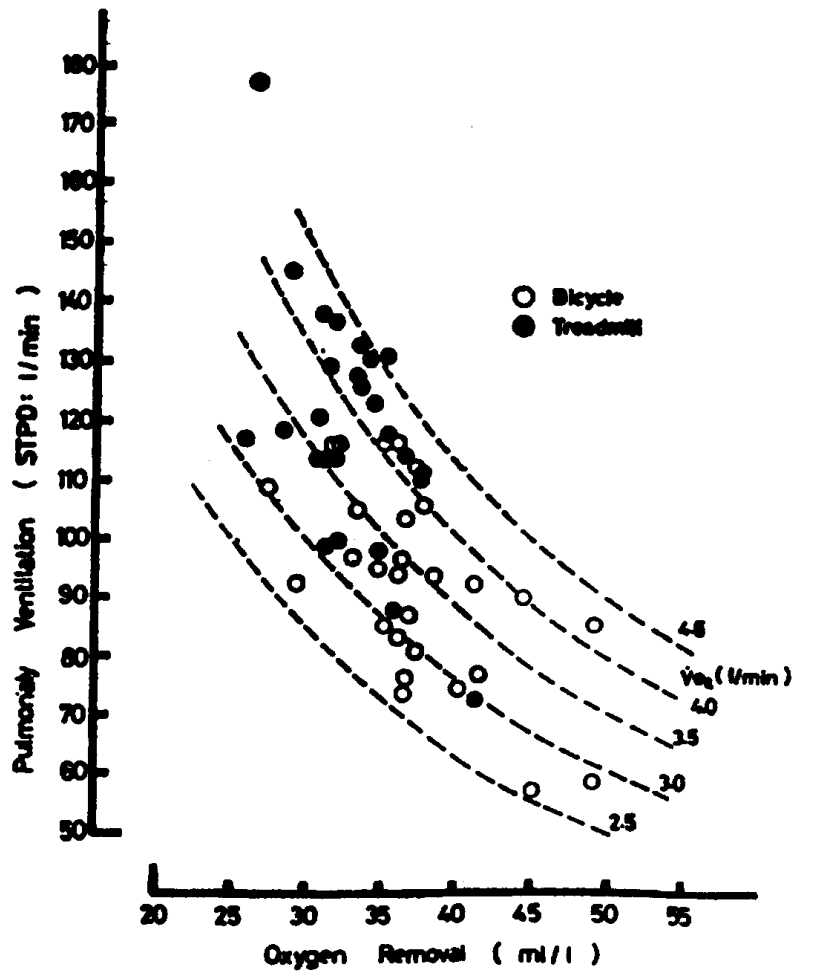

Figure 2. Individual values for maximal oxygen uptake, ventilation (STPD) and oxygen removal during both maximal bicycle exercise and treadmill running. 
式によって呼吸様式が晎なることを示㖅的なるの であり,トレッドミル走では自枟車眼に比较し て呼吸の深さは浅く，呼吸数は多いことが予酎さ れる.トレッドミル走の最大酸莱提取是が自枟車

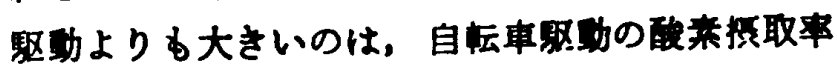
かトレッドミル走よりる高いにすかかわらず,そ れ以上にトレッドミル走の最大作莱時の肺换気息 が自枟車俚功のそれよりる多いことに起因してい

\section{ろ (Fig 2).}

肺换気王が多いことは肺狍でのガス交换に次の

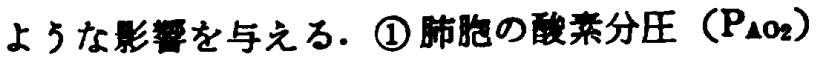
を高めること，(2)拡散面称を広げること，(3)肺胞 膜の膨張によって肺胞膜が薄くなる。したがっ て，トレッドミル走にみられる多い肺换気量は肺 胞䑏のガス交换を自枟車取動よりる優位化促進す るものと考えられる.このことは，本研究のトレ ッドミル走における最大作莱時の肺抬散容量が自 忶車駆動よりる統計的に高いことの大きな要因と 考えられる (Fig 3).

トレッドミル走における奴大作業時の心拍数は 自枟車眼功よりる統計的に有意に高い。このトレ ッドミル走での高い心拍数はトレッドミル走が自

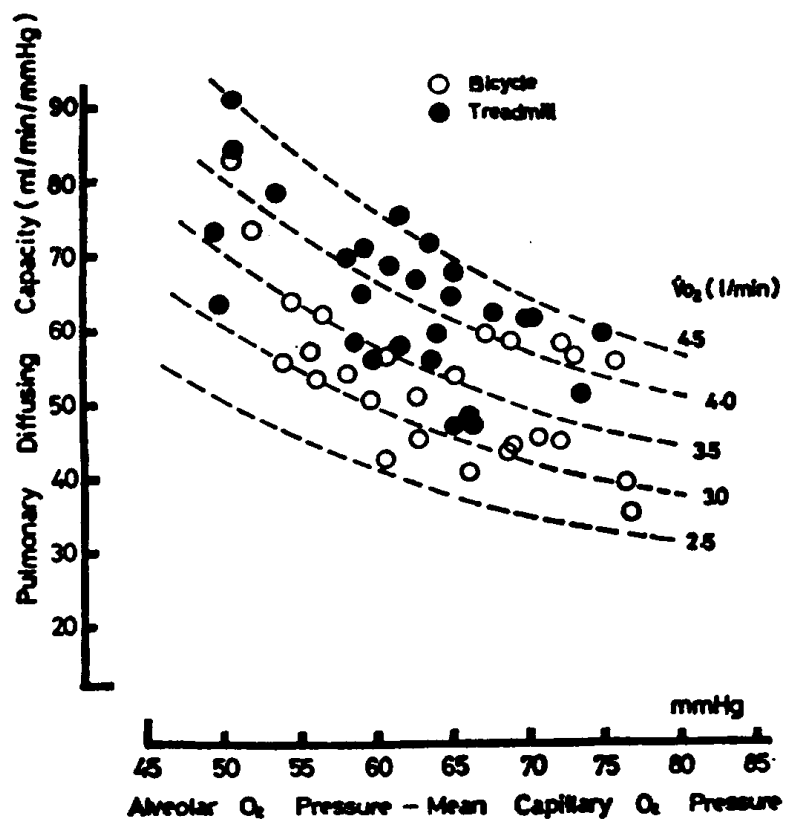

Figure 3. Individual values for maximal oxygen uptake, pulmonary diffusing capacity and difference in alveolar oxygen pressure and mean capillary oxygen pressure during both maximal bicycle exercise and treadmill running

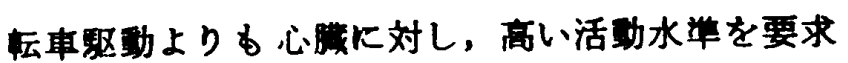
して exhaustionに䢖していることを示している。 ナなわち，自枟車取功が心腈機能の活较を取大限 に発揮する前に何らかの原因によって運坊の持粉 が妨げられているるのと推宗される。

Pirnay ら53は自枟車取功における脚の血流是が 作業強度および心拍数の增加に対してほぼ直的 飞增加することから，自枟車取功中の脚筇の血流 量か酸亲摄取量の基本的制限因子と考えられない としている.しかし、これまでの多くの報告で

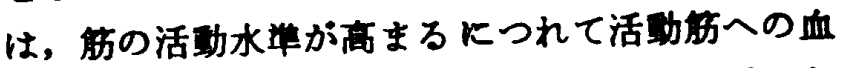
流量は增大寸るが20,20,81,24,40,50,55)，施活功がさら に高まると第内圧の上昇によって血管閏塞が生じ 血流量はむしろ減少すると考光られる $7,13,18,27,58$, os).

Fringer $と$ Stull ${ }^{21)}$, Hermansen $5^{23)}$, Shephard ${ }^{(7)}$, Sugimotoら ${ }^{72)} は$, トレッドミル走の掫

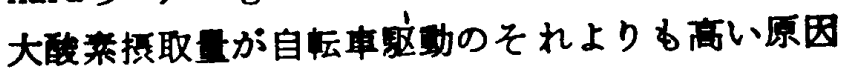
として，トレット゚ミル走時の心拍出量と一回拍出 量が自枟車駆動よりる高いことを誉げている，さ らК，この両作業にみられる心拍出量および一回 拍出量の相違が筋の収樎時間 (contraction-time)

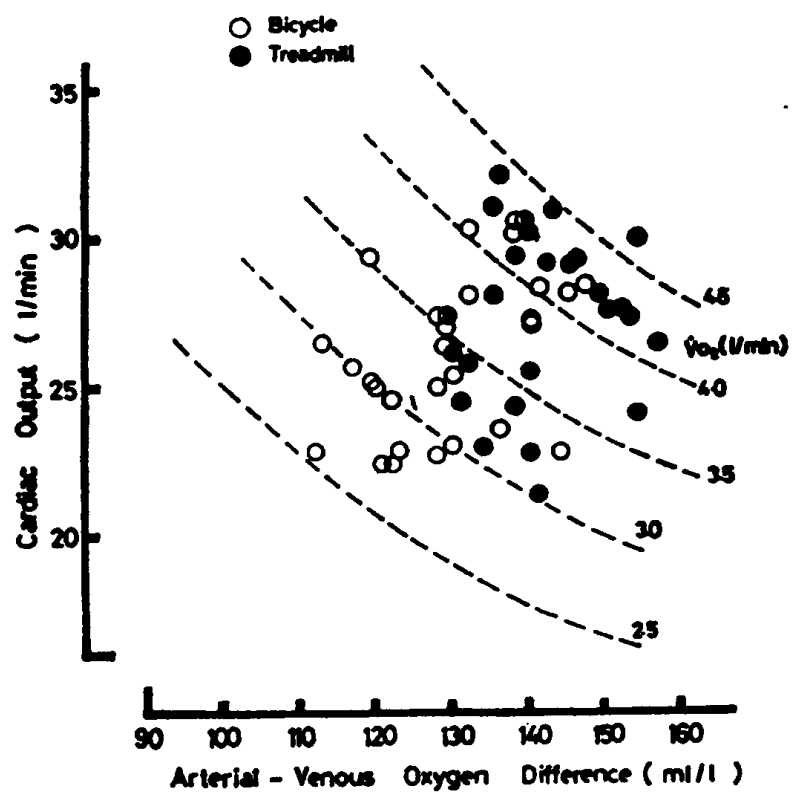

Figure 4. Individual values for maximal oxygen uptake, cardiac output and difference in arterinal oxygen pressure and venous oxygen pressure during both maximal bicycle exercise and treadmill running. 
の美是による情通血流量の相之によるとみなして

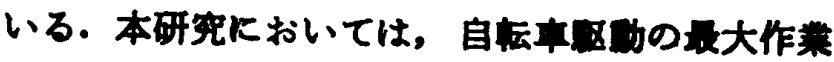
时の心拍出典および一回拍出年と、トレッドミル

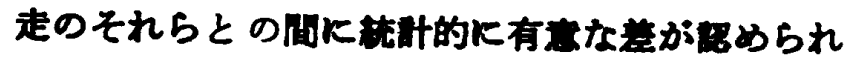

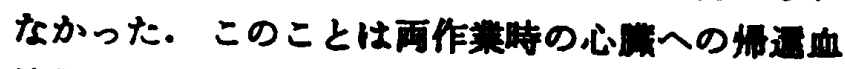

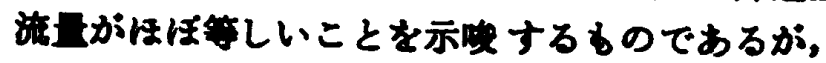
前㲹の多くの赫告と县なるるのであった。 その原 因は明らかではないが，本研究の詨像者が触者 であることる一覃因と考えられる。

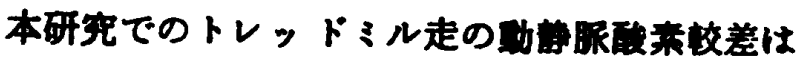

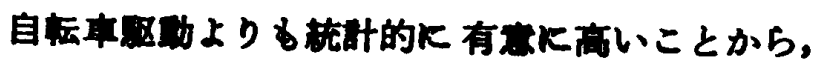

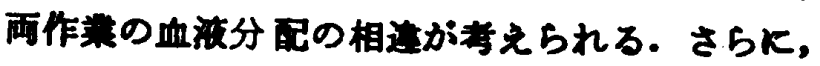
本研究のトレッドミル走と自枟市四政にみられる

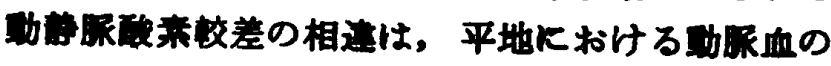
酸来的包和度が作粪棁式および强度に网係なく一定

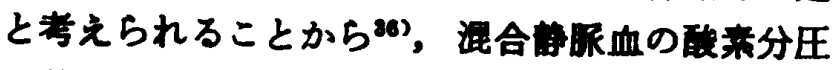

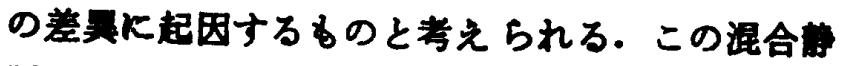

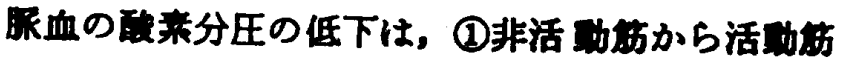

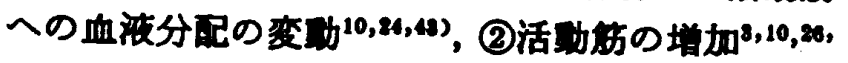
80,47,64), (3)活场坋での酸来の凤きとり (extraction)

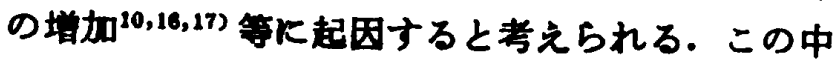
です，本研究においては，两作萧の心拍出量およ び一回拍出目に差暴が愢められないことから，雨 作莱における血㳸分眍の相远に上るところが大き

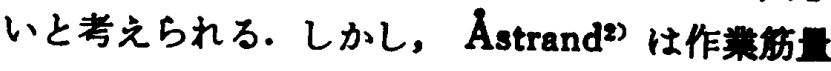
の增大に比例して酸来提取昷が堷加することか ら，Peripheral factor K曂大酸来摄取量の規定因 子が存在するとした。また, Taylor ら ${ }^{73)}$, Gleser

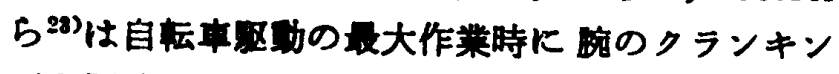
グを同時に行なわせることによって，トレッド

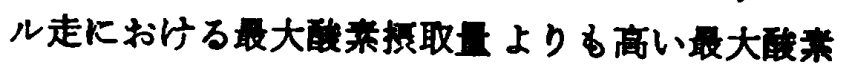
摄取策を報告している，そして，その差異の原因 として作䅈に参与する施量の增加を举げている。 また, Miyamura と Honda(i), Katch ら ${ }^{\text {(8) }}$ はト

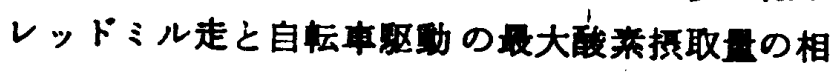

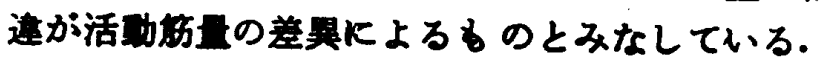
これらのことから，本研究の両作䅈にみられる最

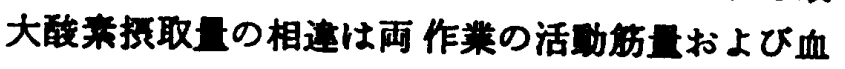
没分目の相䢖に起因するるのと推祭されよう。

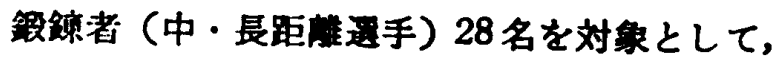

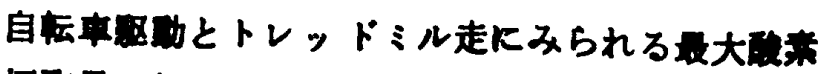

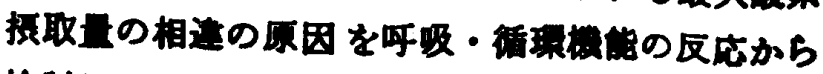

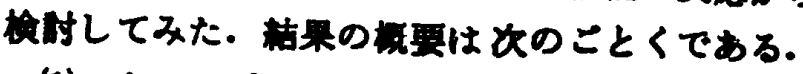

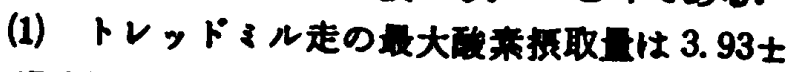
$0.47 \mathrm{l} / \mathrm{min}(67.1 \pm 5.8 \mathrm{ml} / \cdot \mathrm{kgmin})$ となり, 自枟事四の $3.36 \pm 0.501 / \mathrm{min}(57.7 \pm 7.0 \mathrm{ml} /$

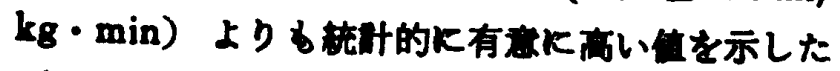
(p<0.001).

(2) トレッドミル走の肺摸気是は $144.31 / \mathrm{min}$

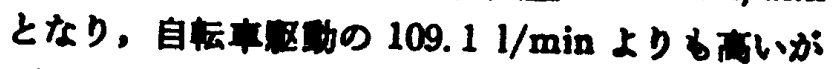

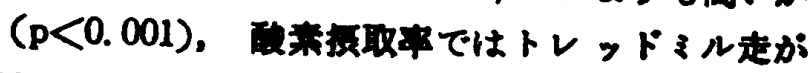

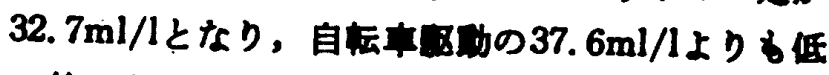
い俌であった(p<0.01).

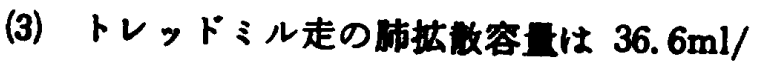

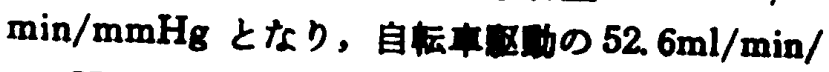
$\mathrm{mmHg}_{\mathrm{g}}$ よりも高い值であった $(\mathrm{p}<0.001)$.

(4) トレッドミル走の心拍出量および一回拍出 吾はそれそれ $27.4 \mathrm{l} / \mathrm{min}, 143.2 \mathrm{ml}$ となり，自忶

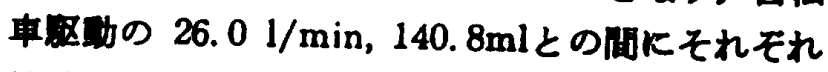
統籵的に有意な差が昭められなかった。しかし，

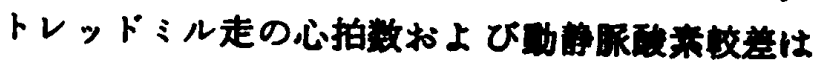
それそれ, 191.5 beats/min, $142.1 \mathrm{ml} / 1$ となり， 目枟車取期の 183.3 beats $/ \mathrm{min}, 129.2 \mathrm{ml} / 1$ より も高い値を示した $(p<0.001)$.

これらのことから、トレッドミル走の高い取大

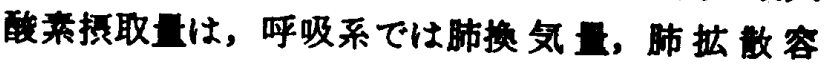

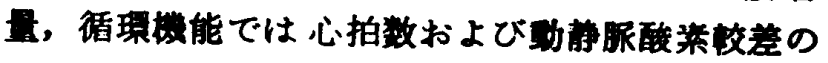
高いことに起因すると考光られよ5。

\section{引用 女 补}

1) Andersen. K. L., A. Bolstad, Y. Loyning and L. Irving, Physical fitness of Arctic Indians. J. Appl. Physiol. 15 : 645-648, 1960.

2) Astrand, P. - O., Experimental studies of physical working capacity in relation to sex and age. Munksgard, Copenhargen, 1952.

3) Astrand, P.-O. and B. Saltin, Maximal oxygen uptake and heart rate in various types of muscular activity. J. Appl. Physiol. 18 : 977-981, 1961.

4) Ȧstrand, P.-O., Aerobic work capacity during maximal performance under various condition. Cir. Res. 20 and 21 :202-210, 1967. 
5) Astrand, P.-O., Commen aries. Canad. Med. Ass. J. $98: 820-821.1969$.

6) Balke, B. and R.W. Ware, An experimental study of physical fitness of air force personnel. U.S.A.F. Med. J. $10: 675-888,1959$.

7 ) Barcroft, H. and J. L. E. Millen, The blood flow through muscle during sustained contraction. J. Physiol. 87 : 17-31, 1939.

8) Carey, P., M. Stensland and L.H. Hartley, Comparison of oxygen uptake during maximal work on the treadmill and the rowing ergometer. Med. Sci. Sports. 6 : 101-103, 1974.

9) Cumming, G.R. and R. Danzinger, Bicycle ergometer studies in children. Pediatrics. 32 : 202-208, 1963.

10) Cumming, G.R., Physical activity and cardiovascular health : current levels of fitness. Canad. Med. Ass. J. 98 : 868-877, 1967.

11) Cumming. G. R. and W. Friesen, Bicycle ergometer measurement of maximal oxygen uptake in children. Can. J. Physiol. Pharmacol. $48: 937-946,1967$.

12) Dill, D.B. and C.F. Consolazio, Responses to exercise as related to age and environmental temperature. J. Appl. Physiol. $17: 645-648$, 1962.

13) Dill, D. B., E. E. Phillips, Jr. and D. MacGregor, Training : Youth and age. Ann. N.Y. Acad. Sci. 134: 760-775, 1966.

14) Dill, D. B. and C. Adams, Maximal oxygen uptake at sea level and at $3,090 \mathrm{~m}$ altitude in high school champion runners. J. Appl. Physiol. 38 : 854-859, 1971.

15) Dolgin, P. and G. Lehman, Ein Beitrag zur Physiologie der statisch en Arbeit. Int. Z. angew. Physiol. 2 : 248-252, 1930.

16) Ekblom, B. and L. Hermansen, Cardiac output in athletes. J. Appl. Physiol. 25 : 619$625,1968$.

17) Ekelund, L.-G. and A. Holmgren, Circulatory and respiratory adaptation during long-term, non-steady state exercise in the sitting position. Acta Physiol. Scand. 62:240-255, 1967.

18) Faulkner, J.A., D. E. Roberts, R.L. Fik and J. Conway, Cardiovascular responses to submax- imum and maximam effort cycling and running. J. Appl. Physiol. 30 : 457-461, 1971.

19) Ferguson, R.J., G.G. Marcotte and R.R. Montpetit, A maximal oxygen uptake test during ice skating. Med. Sci. Sports. 1 : 207-211, 1969.

20) Filley, G.F., D.J. MacIntosh and G.W. Wright, Carbon monoxide uptake and pulmonary diffusing capacity in normal subjects at rest and during exercise. J. Clin. Invest. 33 : 530-539, 1954.

21) Fringer, M.N. and G.A. Stull, Changes in cardioreapiratory parameters during periods of training and detraining in young adult females. Med. Sci. Sports. $\theta: 20-25,1974$.

22) Glassford, R. G., G. H. Y. Baycraft, A. W. Sedgewick and R.B.J. Macnab, Comperison of maximal oxygen uptake values determined by predicted and actual methods. J. Appl. Physiol. $20: 509-513,1965$.

23) Gleser, M. A., D. H. Horstman and R. P. Mello, The effects on $\dot{V}_{2} \max$ of adding arm work to maximal leg work. Med. Sci. Sports. 6 : 104-107, 1974.

24) Grimby, G., N. J. Nilsson and B. Saltin, Cardiac output during submeximal and meximal exercise in active middle-aged athletes. J. Appl. Physiol. 21 : 1150-1156, 1966.

25) Hermansen, L. and B. Saltin, Oxygen uptake during maximal treadmill and bicycle exercise. J. Appl. Physiol. 28 : 31-37, 1969.

26) Hermansen, L., B. Ekblom and B. Saltin, Cardiac output during submaximal and maximal treadmill and bicycle exercise. J. Appl. Physiol. 29 : 82-86, 1970.

27) Holmér, I., Oxygen uptake during swimming in man. J. Appl. Physiol. $33: 502-509,1972$.

28）猪同遉夫，石井吾八，中村度子：血流量汃らみ大第 持久力V. 体腈の科学，15：404-410，1965.

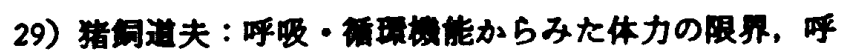
吸と俩环，18：449-456，1968.

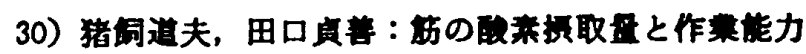

1. 体青の科学, $10: 128-134,1968$.

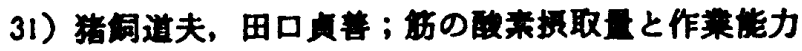

I. 体育科学，18：188-194，1968.

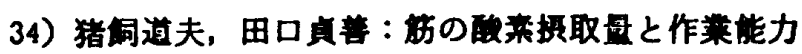


】.体角の科学, $18: 265-269,1968$.

35) Ikai, M., M. Shindo and M. Miyamura, Aerobic work capacity of Japanese people. Res.

J. Physical. Ed. 14: 137-142, 1970.

36) Johnson, R. L., Pulmonary diffusion as a limiting factor in exercise stress. Cir. Res. $20: 154-160,1967$.

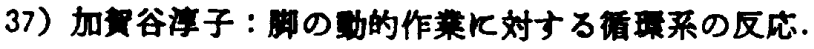
東京家政学院大学紀要，12:75-84，1972.

38) Katch. F.I., W.D. McArdle and G.S. Pechar, Relationship of maximal leg force and composition to treadmill and bicycle ergometer maximum oxygen uptake. Med. Sci. Sports. 6 : 38 $-43,1974$.

39) Klausen, $\mathrm{K}$., Comparison of $\mathrm{CO}_{2}$ rebreathing and acetylene methods for cardiac output. J. Appl. Physiol. 20 : 763-766, 1965.

40) Lind, A.R. and G. W. McNicon, Local and central circulatory responses to sustained contractions and the effect of free or restricted arterial inflow on post-exercise hyperaemia. J. Physiol. 192 : 575-593, 1967.

41) Magel, J.R. and J. A. Faulkner, Maximum oxygen uptake of college swimmers. J. Appl. Physiol. 22 : 929- $138,1967$.

42) Maksud, M.G. and K.D. Couttes, Comparison of a continuous and discontinuous graded treadmill test for maximal oxygen uptake. Med. Sci. Sports. 3 : 63-65, 1671.

43) Margaria, R., F. Mangili, F. Cuttica and P. Cerretelli, The kinetics of the oxygen consumption at the onest of muscular exercise in man. Ergonomics. 8: 49-54, 1965.

44) McArdle, W. D. and J. R. Magel, Physical work capacity maximum oxygen uptake in treadmill and bicycle exercise. Med. Sci. Sports. 2 : 118-123, 1970.

45) McArdle, W.D., F.I. Katch and G.S. Pechar, Comparison of continuous and discontinuous treadmill and bicycle tests for max $\dot{V}_{2}$. Med. Sci. Sports. $5: 156-160,1973$.

46) Metz, K. F. and J. F. Alexander, An investigation of the relationship between maximum aerobic work capacity and physical fitness in twelve to fifteen-year-old boys. Res. Quart.
$41: 75-81,1970$,

47) Miyamura, M. and Y. Honda, Oxygen intake and cardiac output during maximal treadmill and bicycle exercise. J. Appl. Physiol. 32 : 185 $-188,1972$.

48) Mocellin, R. and J. Rutenfrang, Investigations of the physical working capacity of obese children. Acta Pedia. Scand. Suppl. 217 : 77-79, 1971.

49) Moody, D. L., J. Kollias and E. R. Buskirk, Evaluation of aerobic capacity in lean and obese women with four test procedures. J. Sports Med. and Physical Fitness. $8:$ 1-9, 1969.

50) Nagel, F. J. and R. Pellegrino, Changes in maximal oxygen uptake in high school runners over a competitive track season. Res. Quart. $42: 456-459,1971$.

51) Newton, J.L., The assessment of maximal oxygen intake. J. Sports Med. and Physical Finess. $3: 164-169,1963$.

52) Nghiem, Q.X., M. H. Schreiber and L.C. Harris, Cardiac volume in normal children and adolescents. Cir. 35 : 509-522, 1967.

53) Nilsson, B. and D. H. Ingvar, Intramuscular pressure and contractile strength related to muscle blood flow in man. Scand. J. Clin. Lab. Invest. Suppl. 98 : 31-38, 1967.

54) Pirnay, F., R Deroanne and J. M. Petit, Maximal oxygen consumption in a hot environment. J. Appl. Physiol. 28 : 642-645, 1970.

55) Pirnay, F., R. Marechal, R. Radermecher and J.M. Petit, Muscle blood flow during submaximal and maximal exercise on a bicycle ergometer. J. Appl. Physiol. 32 : 210-212, 1972.

56) Pugh, L.G.C.E., Cardiac output in muscular exercise at $5,800 \mathrm{~m}(19,000 \mathrm{ft})$. J. Appl. Physiol. $19: 441-447,1964$.

57) Pugh, L.G.C.E., Athletes at altitude. J. Physiol. 192 : 619-646, 1967.

58) Pugh, L.G.C.E., Oxygen intake in track and treadmill running with observations on the effect of air resistance. J. Physiol. 207 - 823835, 1970.

59) Pugh, L.G.C.E., Maximum oxygen intake in Himalayan Mountaineers. Ergonomics. $15: 133$ 
$-137,1972$.

60) Saltin, B., Aerobic and anerobic work capacity after dehydration. J. Appl. Physiol. 19 :

$1114-1118,1964$.

61) Saltin, B., Circulatory response to submaximal and maximal exercise after thermal dehydration. J. Appl. Physiol. $18: 1125-1132,1964$.

62) Saltin, B. and J. Stenberg. Circulatory response to prolonged severe exercise. J. Appl. Physiol. $19: 833-838,1964$.

63) Saltin, B. and P.-O. Astrand, Maximal oxygen uptake in athletes. J. Appl. Physiol. 23 : 353-358, 1967.

64) Shephard, R. J., The prediction of maximal oxygen consumption using a new progressive step test. Ergonomics. 10:1-15, 1967.

65) Shephard, R. J., The heart and circulation under stress of olympic conditions. J. A. M. A. $205: 775-779,1968$.

66) Shephard, R. J., C. Allen, A. J. S. Bepade, C.T.M. Davies, P. E. Prampero, R. Hedman, J. E. Merriman, K. Myhre and R. Simmons, The maximum oxygen intake. Ball. Wld. Hith. Ory. $38: 757-764,1968$.

67) Škranc, O., V. Havel and K. Banták, A comparison of work capacity measured by graded step-test and on a bicycle ergometer. Ergonomics. 13:675-683, 1970.

68) Start, K. B. and R. Homes, Local muscle endurance with open and occluded intramuscu- lar circulation. J. Appl. Physiol. $18: 804-807$. 1963.

69) Stenberg, J., B. Ekblom and K. Messin, Hemodynamic response to work at simulated altitude, 4,000m. J. Appl. Physiol. 21 : 15891594, 1966.

70) Strydom, N. B., C.H. Wyndham, C. G. Williams, J. F. Morison, G. A. G. Bredell, A.S.S. Benade and M. V. Rahden, Acclimatization to humid heat and the role of physical conditioning. J. Appl. Physiol. 21 : 636-642, 1966.

71) Sugimoto, T., K. Sagawa and A. C. Guyton, Effect of tachycardia on cardiac output during normal and increased venous return. Am. J. Physiol. 211 : 288-292, 1966.

72) Taylor, H. L., E. Buskirk and A. Henschel, Maximal oxygen intake as an objective measure of cardio-respiratory performance. J. Appl. Physiol. 8 : 73-80, 1955.

73) Wyndham, C.H., N.B. Strydom, W.P. Leary and C.G. Williams, Studies of the maximum capacity of men for physical effort. Int. $Z$. angew. Physiol. 22 : 285-295, 1966.

74) Wyndham, C. H., N. B. Strydom, A. J. Rensburg, A.J.S. Benade and A.J. Heyns, Relation between $\dot{V} o_{2} \max$ and body temperature in hot humid air conditions. J. Appl. Physiol. 29 : 4550, 1970.

75）山地啓司, 猪同道夫 : 有酸菜的作莱能の一因子とし ての肺㹡散容量. 体育学研究, $17: 7-16,1972$. 